University of Baghdad

College of Engineering

J愿

JOURNAL OF ENGINEERING
Journal of Engineering

journal homepage: www.joe.uobaghdad.edu.iq

Number 3 Volume 25 March 2019

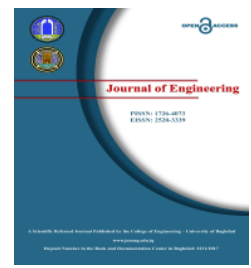

Electrical, Electronics and communications, and Computer Engineering

\title{
Digital Color Image Watermarking Using Encoded Frequent Mark
}

\author{
Abdulkareem Mohammed Salih* \\ Assist Lecturer \\ Al-Dour Technical Institute-Northern Technical \\ University \\ abdulkreem86@gmail.com
}

\author{
Salih Hassan Mahmood \\ Assist Lecturer \\ Al-Dour Technical Institute-Northern Technical \\ University \\ saleh_hassan64@yahoo.com
}

\section{ABSTRACT}

With the increased development in digital media and communication, the need for methods to protection and security became very important factor, where the exchange and transmit date over communication channel led to make effort to protect these data from unauthentication access.

This paper present a new method to protect color image from unauthentication access using watermarking. The watermarking algorithm hide the encoded mark image in frequency domain using Discrete Cosine Transform. The main principle of the algorithm is encode frequent mark in cover color image. The watermark image bits are spread by repeat the mark and arrange in encoded method that provide algorithm more robustness and security. The proposed algorithm efficiency is measured by using many of measurement factors such as Peak Signal to Noise Ratio PSNR and Normalized Correlation Coefficient NC, the watermark robustness and feasibility are measured by using many types of attacks.

Key words: watermarking, security, robustness.

\section{العلامة المائية للصور الرقية الملونة باستخدام العلامة المثفرة المكررة}
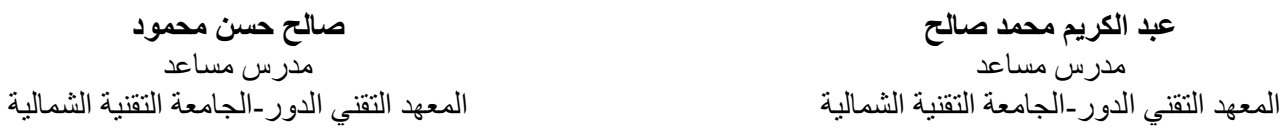

\section{الخلاصة}

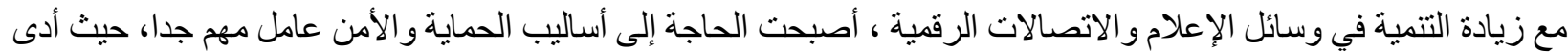

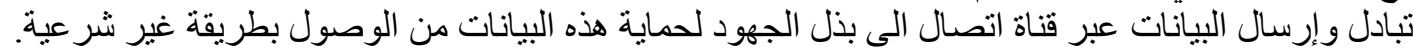

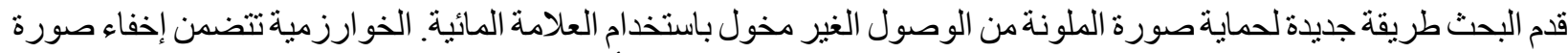

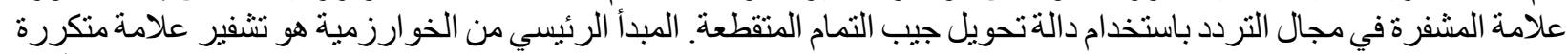

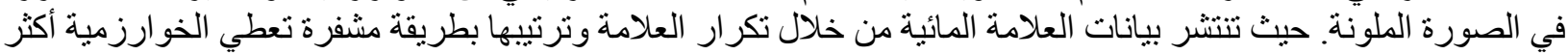

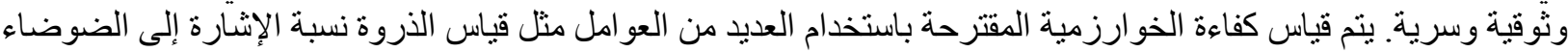
و ومعامل الارتباط الطبيعي NCSN كلمات رئيسية: العلامة المائية , الأمنية , متانة.

\footnotetext{
*Corresponding author
}

Peer review under the responsibility of University of Baghdad. https://doi.org/10.31026/j.eng.2019.03.07

2520-3339 @ 2019 University of Baghdad. Production and hosting by Journal of Engineering.

This is an open access article under the CC BY-NC license http://creativecommons.org/licenses/by-nc/4.0/).

Article received: $12 / 3 / 2018$

Article accepted: $21 / 6 / 2018$ 


\section{INTRODUCTION}

The process of embedding invisible signal in an image called Digital Watermarking Image. This process consider a form of copyright Protection, ElGamal, et al., 2013. Watermarking classify according to many parameters, at first according to the domain of embedding and extraction where two domain are used spatial domain and frequency domain. The spatial domain used the cover image without convert it to frequency domain and it is characterized by simplicity and less immunity to attacks where as in frequency domain the cover image transfer to frequency domain using Discrete Cosine Transform (DCT) or Discrete Wavelet Transform (DWT), the transform coefficients modified by the mark value, then to get the mar image, one should perform the transform inversely, Hajjara , et al. , 2009. The visibility is another parameter to classification where there are two types: visible watermarking and invisible watermarking, visible water mark is clearly detectable. While the invisible watermarking is used to identify the owner or the origin of the host image, Giri ,et al. ,2015. Many techniques for color image watermarking are presented, Some of these techniques focus on spatial domain as in Dharwadkar, and Amberker, 1999, where the paper focus on the average intensity which is estimated from the intensities of the R, G and B components. In Abdallah, and Hammo, 2006, deals with colored images in the biological color model, the Hue, Saturation, and Intensity (HSI), where the method robustness is tested against several attacks. Watermark security is increased by using the Hadamard transform matrix .Another part of researches focus on the transform domain using (DCT) as in Abraham, and Paul, 2016, it uses Discrete Cosine Transform to transform the host image into frequency domain for selecting appropriate coefficients for watermark embedding. Wavelet transform is another type of the transform domain which provide the property of multi-Resolution analysis, many of searcher focus on this property as in Sharma, and Prashar, 2012 .There are papers merge more of transform as in ElGamal, et al. , 2013, the searchers joined between DCT and (DWT) which take advantage of the two frequency domains.

The main objective in the proposed paper is to present the hiding watermark in color cover image using encoded frequent mark embedded in frequency hopping since much than one frequency are used to embed the watermark in DCT blocks for get more security, then the watermark image is extracted at the receiver without need for origin image. The rest of this paper is organized as follows: In Section 2 Discrete cosine Transform explained. Section 3 discusses the Basic watermarking criterias.Watermark Embedding and Watermark Extraction respectively explained in section 4 and section 5. Error and Correction Ratio are explained in Section 6. Section 7 contain Encoded and Frequent Stage. Simulation Results are discussed in Section 8. Finally, Section 9 concludes the paper.

\section{DISCRETE COSINE TRANSFORM}

Discrete Cosine Transform (DCT) can be defined is a transformation algorithm that converts images from spatial domain to frequency domain EIGamal, et al. ,2013. Carried out watermarking need to change the transform coefficients and the DCT watermarking is more robust compared to the spatial domain Hajjara, et al. , 2009 .

\section{BASICS WATERMARKING CRITERIAS}

Watermarking algorithm to be efficient, many criterias should be obtained or saved as explained:-

1- Invisibility: which means the quality of cover image should not be effected and cannot be explained by users Giri, et al., 2015. 
2- Robustness: Means the immunity to the various signal operation that can be obtain during transmit such as noise ,compression and resizing Patel ,and Tahilramani ,2016.

3- Security: can be defined as the ability to resist hacking attempts to remove the mark without modified cover image Hui-fang, et al., 2010.

4- Capacity: means amount of information bits can be inserted in cover image EIGamal, et al. , 2013.

\section{PROPOSED WATERMARK EMBEDDING}

As shown in Fig.1, many stages are used in embedding side, these stages explained as:

1- Convert the color image from RGB components to YCbCr components. Since the Luminance $(\mathrm{Y})$ is less sensitive for human.

2- The Luminance $(\mathrm{Y})$ layer convert to $(8 * 8)$ non-overlapped DCT domain. The size of $(8 * 8)$ standard as in Abraham, and Paul, 2016.

3- For the mark, encoded frequent mark is used, where the binary image mark is used and the mark is encoded in way that depend on repeated the bits value of mark and reposition these bit in a sequence predefined at Extraction side. This step consider the main aim for this algorithm, where the criterias of watermarking image are saved. The number of repeated is commensurate extrusive with capacity criteria, where as directly proportional with security and robustness criterias.

4- The encode bits are insert in frequency domain layer of cover image, middle frequency positions are used for insertion and these positions selected using predefined secret key.

5- Convert the Luminance component ( $\mathrm{Y}$ ) from Frequency domain to spatial domain. Convert $\mathrm{YCbCr}$ components to RGB components to obtained watermarked image.

\section{PROPOSED WATERMARK EXTRACTION}

At the receiver side in Fig.2 backward steps are used to recover mark image as explain:

1- Convert the watermarked color image from RGB components to $\mathrm{YCbCr}$ components.

2- Convert the Luminance component (Y) to Frequency domain to.

3- Select the position of insertion mark value, where the middle frequencies are used and these positions can be selected depend on secret key.

4- After extract the mark value, decode stage is used which include obtaining a one copy of mark image. The number of copy and rules of select sequence mark value are predefined in Embedding stage.

5- The value of the sequence is threshold to ' 1 ' or ' 0 '.

\section{ERROR AND CORRECTION RATIO}

The quality of the watermarked image can be calculated by finding the value of Peak Signal to Noise Ratio PSNR Sharma, and Prashar, 2012, as shown: 
$\mathrm{PSNR}=10 \log 102552 / \mathrm{RMSE}$

Where the RMSE is root mean square error and equal to:

$R M E S=1 /(M * N) \sqrt{\sum_{i=1}^{M} \sum_{j=1}^{N}[\mathrm{I}(\mathrm{i}, \mathrm{j})-\mathrm{f}(\mathrm{i}, \mathrm{j})]^{2}}$

$\mathrm{M}$ and $\mathrm{N}$ are image dimensions (number of pixels) $(\mathrm{M}=\mathrm{N})$. The similarity between extracted mark and the origin mark can be calculated by finding the Normalized correlation coefficient NC as in Eq. (3):

$N C=\sum_{i=1}^{M} \sum_{j=1}^{N} w(i, j) w^{*}(i, j) / \sum_{i=1}^{M} \sum_{j=1}^{N} w(i . j)^{2}$

Where $\mathrm{w}(\mathrm{i}, \mathrm{j})$ and $\mathrm{w}^{*}(\mathrm{i}, \mathrm{j})$ represent the origin and extracted watermark respectively. The value of NC equal to1 as maximum value Zubair , et al. ,2009.

\section{ENCODED AND FREQUENT STAGE}

This stage include two steps, the first step make numbers of copy of mark and this number is commensurate extrusive with security and robustness criteria where as inversely proportional with the Capacity and PSNR for the watermarked image. Fig.3 show the ratio between the PSNR and the number of mark copies. Second step include redistribution the bits sequence of the copies in away predefined at embedding and extraction stage.

\section{SIMULATION RESULTS}

In order to test the proposed algorithm, color $(512 * 512)$ pixels images are used. Lena, Peppers and Airplane image used as cover images.In other side binary images size (64x64) pixels is used as mark image. The size of $(512 * 512)$ constribte in capacity criteria. PSNR calculated to depend it as criteria metrics (it calculated for Number of mark copy =2). Table 1 show the value of PSNR While Table 2 show Normal Correlation and how it effect during transmitted or attack by hackers and these process may changed or modified.

\section{CONCLUSION}

New proposed algorithm presented in this paper for watermarking digital color image. This algorithm focus on away where make the criterias of watermarking are most important properties. Color image cover has three layers of color and one of these layer is used. The number of copies that can be inserted in this layer may be one copy or more ,this depend on the value of PSNR for watermarked image where the PSNR will reduce when the number of copies increased as shown in the graphs in Fig.3 and the property of capacity achived. The redistribution of these copies give a security form for algorithm since the position of bits injection are known only in the extraction stage and it will contibute in increasing the security criteria. Techniques are used such as the position of insertion in DCT domain and position of insertion in over all the image led to reduce the effect of attacks on the watermarked image and as a result the robutness became agood. These properties are explained in results obtain as shown in Table 1 and 2. Five types of attacks are used and the value of $\mathrm{NC}$ obtained from extracted mark used as factor for the good robustness of the algorithm as compared with Imran,and Harvey , 2017 and other referenced mentied in with Imran,and Harvey, 2017 as shown in Table 3. 


\section{REFERENCES}

- $\quad$ ElGamal, A, F, Mosa, N.A. and ElSaid, W. K. , 2013 ,Block-based Watermarking for Color Images using DCT and DWT, International Journal of Computer Applications, Vol. 66, No.15, PP. $0975-8887$.

- Hajjara, S. , Abdallah, M. , and Hudaib , A.2009 ,Digital Image Watermarking Using Localized Biorthogonal Wavelets, European Journal of Scientific Research,Vol.26, No.4, PP.594-608.

- Giri, K. J., Peer, M.q A. and Nagabhushan, P., 2015, A Robust Color Image Watermarking Scheme Using Discrete Wavelet Transformation, I.J. Image, Graphics and Signal Processing,Vol.7, No.1, PP. 47-52.

- Patel, Sh. K.J. , Tahilramani, N. V. , 2016, Information Hiding Techniques: Watermarking, Steganography: A Review, International Journal of Innovative Research in Electrical, Electronics, Instrumentation and Control Engineering Vol. 4, No. 4, PP. 168-173.

- Hui-fang, LI, Ning, CH., and Xiao-ming, CH. ,2010, A Study on Image Digital Watermarking Based on Wavelet Transform ", The Journal of China Universities of Posts and Telecommunications, (Suppl.),Vol. 17,No. 1,PP. 122-126.

- $\quad$ Sharma, Ch., Prashar,D. , 2012, DWT Based Robust Technique of Watermarking Applied on Digital Images, International Journal of Soft Computing and Engineering (IJSCE) ISSN: 2231-2307, Vol. 2,No. 2 , PP. 399-402.

- Zubair, A. R. , Fakolujo, O. A., and Rajan, P.K. ,2009, Digital Watermarking Of Still Images With Color Digital Watermarks, EUROCON 2009, EUROCON '09. IEEE, Vol.64, No.1, PP.18-23.

- Abraham, J. and Paul, V. , 2016, A DCT Based Imperceptible Color Image Watermarking Scheme, International Journal of Signal Processing, Image Processing and Pattern Recognition Vol.9, No.7, pp.137-146.

- Dharwadkar, N. V. and Amberker, B. B. ,1999, Secure Watermarking Scheme for Color Image Using Intensity of Pixel and LSB Substitution, School of Information Technology and Engineering,Vol.1,No.1,PP. 1-6.

- Abdallah, D. M. , and B. Hammo, 2006, Dual Domain Watermarking in the Biological Color Model, IEEE InternationalConference on Information and Automation (ICIA), pp. 407411.

- Imran,M. and Harvey,B.,A. ,2017, A Blind Adaptive Color ImageWatermarking Scheme Based on Principal Component Analysis, Singular Value Decomposition and Human Visual System, Radioengineering, Vol.26,No.3,PP. 823-834 


\section{NOMENCLATURE:}

$\mathrm{YCbCr}=$ Luminance and Chrominance

$\mathrm{NC}=$ Normal Correlation Coefficient

$\mathrm{PSNR}=$ Peak Signal to Noise Ratio

RGB: Red, Green, and Blue

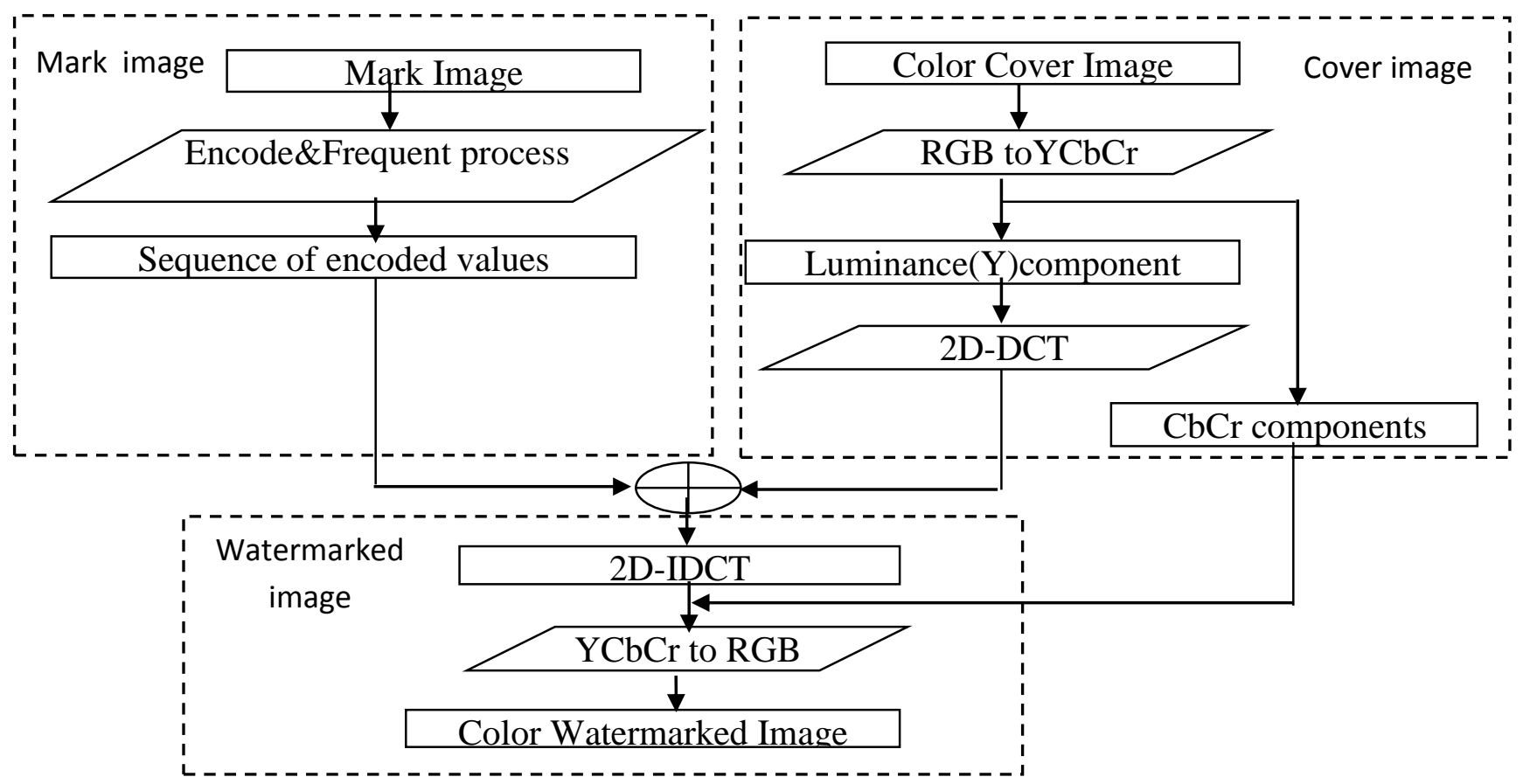

Figure 1. Proposed Algorithm for Watermark Embedded.

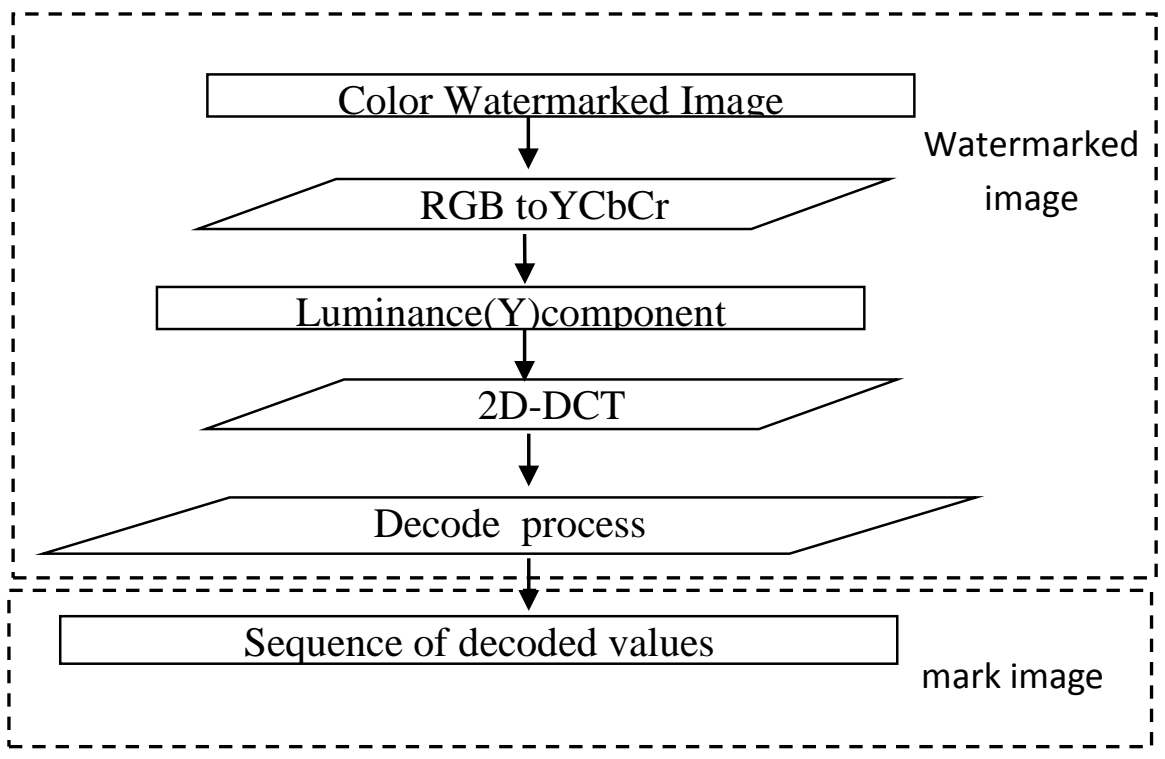

Figure 2. Proposed Algorithm for Watermark Extraction. 


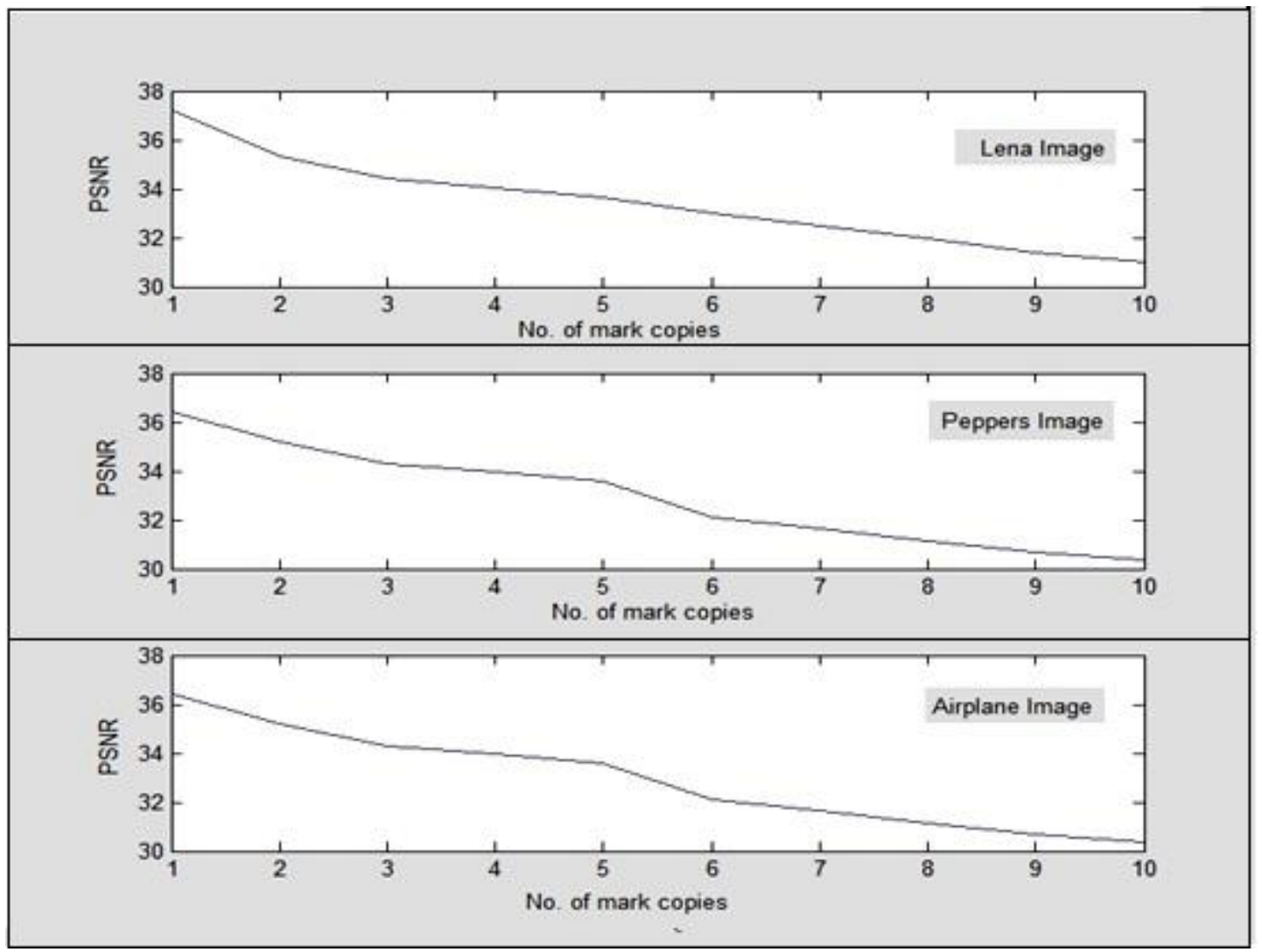

Figure 3. Ratio between PSNR and Number of Mark Copies.

Table 1. PSNR for Watermarked Color Image.

\begin{tabular}{|c|c|c|}
\hline & \\
\hline & & \\
\hline
\end{tabular}


Table 2. NC for Extracted Mark Image.

\begin{tabular}{|c|c|c|c|c|c|c|}
\hline \multicolumn{7}{|c|}{ Lena Image } \\
\hline $\begin{array}{l}\text { Type of } \\
\text { Attacks }\end{array}$ & $\begin{array}{l}\text { Without } \\
\text { attack }\end{array}$ & $\begin{array}{c}\text { Cut part } \\
\text { from image }\end{array}$ & LPF & $\begin{array}{l}\text { Salt and } \\
\text { Peppers }\end{array}$ & $\begin{array}{l}\text { Mean } \\
\text { Filter }\end{array}$ & $\begin{array}{l}\text { Gaussian } \\
\text { Filter }\end{array}$ \\
\hline $\mathrm{NC}$ & 1 & 0.998 & 0.996 & 0.953 & 0.966 & 0.972 \\
\hline $\begin{array}{c}\text { Extracted } \\
\text { Mark } \\
\text { Image }\end{array}$ & & & & & & \\
\hline \multicolumn{7}{|c|}{ Peppers Image } \\
\hline $\begin{array}{l}\text { Type of } \\
\text { Attacks }\end{array}$ & $\begin{array}{l}\text { Without } \\
\text { attack }\end{array}$ & $\begin{array}{l}\text { Cut part from } \\
\text { image }\end{array}$ & LPF & $\begin{array}{l}\text { Salt and } \\
\text { Peppers }\end{array}$ & $\begin{array}{l}\text { Mean } \\
\text { Filter }\end{array}$ & $\begin{array}{l}\text { Gaussian } \\
\text { Filter }\end{array}$ \\
\hline $\mathrm{NC}$ & 1 & 0.999 & 0.952 & 0.946 & 0.9592 & 0.9743 \\
\hline $\begin{array}{c}\text { Extracted } \\
\text { Mark } \\
\text { Image }\end{array}$ & & & & & & \\
\hline \multicolumn{7}{|c|}{ Airplane Image } \\
\hline $\begin{array}{l}\text { Type of } \\
\text { Attacks }\end{array}$ & $\begin{array}{l}\text { Without } \\
\text { attack }\end{array}$ & $\begin{array}{l}\text { Cut part from } \\
\text { image }\end{array}$ & LPF & $\begin{array}{l}\text { Salt and } \\
\text { Peppers }\end{array}$ & $\begin{array}{l}\text { Mean } \\
\text { Filter }\end{array}$ & $\begin{array}{l}\text { Gaussian } \\
\text { Filter }\end{array}$ \\
\hline $\mathrm{NC}$ & 1 & 0.990 & 0.963 & 0.948 & 0.959 & 0.974 \\
\hline $\begin{array}{c}\text { Extracted } \\
\text { Mark } \\
\text { Image }\end{array}$ & & & & & & \\
\hline
\end{tabular}

Table 3. NC Comparsion(Lena Image) for Different Techniques.

\begin{tabular}{|c|c|c|c|c|c|c|}
\hline $\begin{array}{c}\text { Types of } \\
\text { attack }\end{array}$ & $\begin{array}{c}\text { Proposed } \\
\text { Algorithm }\end{array}$ & $\begin{array}{c}\text { Imran,and } \\
\text { Harvey,2017 }\end{array}$ & $\begin{array}{c}{[3] \text { in }} \\
\text { Imran,and } \\
\text { Harvey,2017 }\end{array}$ & $\begin{array}{c}{[6] \text { in }} \\
\text { Imran,and } \\
\text { Harvey,2017 }\end{array}$ & $\begin{array}{c}{[13] \text { in }} \\
\text { Imran,and } \\
\text { Harvey } \\
, 2017\end{array}$ & $\begin{array}{c}{[14] \text { in }} \\
\text { Imran,and } \\
\text { Harvey } \\
, 2017\end{array}$ \\
\hline $\begin{array}{c}\text { Cut part } \\
\text { from image }\end{array}$ & 0.998 & 0.8570 & 0.6322 & 0.6825 & 0.7370 & 0.6216 \\
\hline LPF & 0.996 & - & - & - & - & - \\
\hline $\begin{array}{c}\text { Salt and } \\
\text { Peppers }\end{array}$ & 0.953 & 0.8656 & 0.5270 & 0.7406 & 0.7420 & 0.5436 \\
\hline $\begin{array}{c}\text { Mean Filter } \\
\text { Gaussian } \\
\text { Filter }\end{array}$ & 0.966 & - & - & - & - & - \\
\hline
\end{tabular}

